\title{
A IMPORTÂNCIA DOS ATIVOS ESPECÍFICOS NA DIFERENCIAÇÃO DE FIRMAS DO SETOR HOTELEIRO
}

\section{THE IMPORTANCE OF THE SPECIFIC ASSETS IN DIFFERENTIATION OF FIRMS IN THE HOTEL SECTOR}

Fábio Freitas Schilling Marquesan PPGA da Universidade de Fortaleza - Unifor - CE fabioschilling@yahoo.com.br

Renata Fernandes Guzzo Universidade Federal do Rio Grande do Sul -UFRGS renataguzzo@yahoo.com.br

Paulo Antonio Zawislak Universidade Federal do Rio Grande do Sul -UFRGS paz@ea.ufrgs.br

Jorge Tello-Gamarra Universidade Federal do Rio Grande -FURG jorgetellogamarra@gmail.com

Submissão: $19 / 03 / 2014$

Aprovação: 27/08/2015 


\section{RESUMO}

O objetivo deste trabalho consiste em mensurar os ativos específicos de um grupo de hotéis localizados na cidade de Porto Alegre/RS (Brasil) e analisar o custo de governança dos mesmos em relação ao potencial de diferenciação das firmas que compõem esse setor econômico. O método empregado consistiu na análise detalhada dos sites da internet de 23 hotéis das categorias Luxo e Superior com a finalidade de listar os ativos que cada um deles oferece. Ao total foram analisados 69 ativos capazes de proporcionar diferenciação entre as firmas pesquisadas. Depois, essa lista foi avaliada por dois experts em hotelaria (que atribuíram pesos - zero, 1 e 2 - a cada ativo), de modo que a diferenciação entre as firmas, ponderada em função do peso dos seus ativos, fosse mensurada. A Economia dos Custos de Transação (ECT) responde pelo embasamento teórico deste trabalho, especialmente no que tange à relação custos de governança Vs. especificidade dos ativos. Dos resultados encontrados, destaca-se que as diferenças entre a especificidade dos ativos e os preços das diárias (tomados como indicador dos custos de governança) revelou uma estratificação em quatro grupos (I, II, III e IV), partindo daqueles hotéis que cobram preços mais acessíveis e oferecem poucos ativos específicos até aqueles que cobram mais caro por uma diária mas, em compensação, oferecem mais valor em termos de ativos específicos aos seus hóspedes. Isso confirma a validade, a acurácia e a relevância da ECT para a realização de estudos desta natureza.

Palavras-chave: Ativos específicos, diferenciação, firma, serviços, hotelaria. 


\begin{abstract}
The aim of this paper is to measure the specific assets of a group of hotels located in Porto Alegre/RS (Brazil), and analyzes their governance costs in relation to the differentiation potential between firms that make up this economic sector. The method employed consisted of a detailed analysis of web sites of 23 hotels in the categories Luxury and Superior in order to list the assets offered by each of them. In total were analyzed 69 specific assets capable of providing differentiation between the hotels surveyed. After, this list was evaluated by two experts in hospitality (who attributed weights - zero, 1 and 2 - to each specific asset), so, the differentiation among firms weighted average according to the weight of their specific assets were measured. The Transaction Cost Economics is the theoretical background of this work, specially, in regard to the relationship cost of governance vs. asset specificity. The results found highlighted that the differences between asset specificity and the rates per day (taken as an indicator of the cost of governance) revealed a stratification into four groups (I, II, III and IV), starting from those hotels that charge more affordable prices and offer few specific assets to those who charge more expensive prices for one daily rate, but, in compensation, offer more value in terms of specific assets to their guests. This confirms the validity, accuracy and relevance of ECT for conducting such studies.
\end{abstract}

Keywords: Specific assets, differentiation, firm, services, hospitality. 


\section{INTRODUÇÃO}

Quando Oliver Williamson identificou, nos idos da década de 1970, que as partes envolvidas em uma transação eram, de fato, sensíveis a certos custos não produtivos, mas inerentes às atividades mercantis, definiram-se os contornos fundamentais do corpo teórico que veio a ser conhecido como Economia dos Custos de Transação (ECT). As firmas, quando em uma transação, escolhem mecanismos de coordenação e adotam estruturas de governança na intenção de, justamente, diminuir os custos de transação. Na realidade, os custos de transação são o resultado da diferença de atributos e de sua percepção por parte dos agentes econômicos. Mais do que isso, é a própria obrigatoriedade de transacionar e, por dedução, de incorrer em custos de mercado, que acaba por determinar as diferentes formas de organização das firmas.

Um dos pressupostos básicos da ECT implica que, para sustentar o ímpeto de ser firma - dentro de um padrão que permita a obtenção de lucros a partir das transações econômicas -, a função empreendedora-coordenadora da organização deve se empenhar, incessantemente, em oferecer ao mercado ativos que sejam sempre e, cada vez mais, específicos (visando, claro a diferenciação da firma em relação aos demais agentes econômicos). Portanto, para ser, de fato, uma firma, uma organização precisa inovar, isto é, continuamente ofertar ao mercado produtos e/ou serviços diferenciados.

A capacidade de bem explorar a especificidade dos ativos de uma organização constitui fator que a permite escapar, ainda que por exíguo tempo, da imitação pelos concorrentes. É esse uso dos ativos específicos que, segundo a ECT, tende a conferir a uma dada organização o status de firma. Em suma, é possível depreender que dado um nível de especificidade de ativos, haverá um correspondente nível de organização necessária. Mais do que isso, é possível afirmar que é justamente o nível de especificidade dos ativos que irá determinar o respectivo tipo de organização e os custos de governança a serem praticados pela firma.

Baseado nessa premissa, o objetivo deste trabalho consiste em mensurar os ativos específicos de hotéis localizados na cidade de Porto Alegre/RS, Brasil, e analisar os custos de governança dos mesmos em relação ao potencial de diferenciação das firmas que compõem esse setor econômico.

Justifica-se a escolha do segmento hoteleiro enquanto universo empírico para a realização da pesquisa pela observação de que esta é uma das atividades econômicas cujo 
crescimento tem sido dos mais expressivos em anos recentes. Novos hotéis foram e continuam sendo construídos, enquanto outros ainda passam por uma série de reformas que tanto visam a melhorias na qualidade das instalações e maior conforto aos hóspedes quanto ao aumento da capacidade instalada - o que implica mais unidades habitacionais (quartos e suítes) à disposição dos hóspedes e salas de eventos maiores e em maior quantidade.

A fim de atender a esse tipo de demanda, que é formada, inclusive, por turistas estrangeiros, os serviços de consultas e reservas de hotéis pela internet são cada vez mais procurados, tornando-se imprescindíveis nas transações comerciais atualmente em voga no setor hoteleiro. De acordo com O'CONNOR (2001), o turista contemporâneo requer informações cada vez mais precisas antes mesmo da realização de uma viagem. Tais informações o ajudarão no planejamento dos passeios e na tomada de decisões frente à grande diversidade de produtos e serviços oferecidos pelo segmento turístico. Nesse sentido, fatores como interface amigável e atualização constante das informações nos endereços eletrônicos dos empreendimentos hoteleiros são fundamentais para se conquistar clientes.

Conforme Hocayen-da-Silva e Teixeira (2008), a diferenciação entre as firmas do segmento hoteleiro somente terá sentido se for percebida e interpretada, em termos de valor, pelo público consumidor. Sendo a Web um dos canais de comunicação mais importantes na atualidade, torna-se imperativo às firmas diferenciarem-se não mais apenas em termos de estrutura física, mas também no que diz respeito aos chamados ambientes virtuais. Por conta disso, a decisão quanto ao método empregado neste trabalho foi o de realizar um levantamento dos ativos que são exibidos, como fator de diferenciação, nos endereços eletrônicos (sites de internet) de diferentes hotéis das categorias Luxo e Superior.

Quanto à estrutura, o artigo foi organizado em cinco seções. Além da introdução (primeira seção), apresentamos uma argumentação teórico-conceitual acerca do que é a fïrma e de como ela atua segundo a Economia dos Custos de Transação (segunda seção). Ainda na segunda seção, exploramos a relação esperada entre os custos de coordenação e a especificidade dos ativos envolvidos em uma transação. Posteriormente, expomos o método de trabalho pelo qual se desenvolveu a pesquisa (terceira seção) e, em seguida, discutimos os resultados do trabalho (quarta seção). Por fim, na quinta seção, foram tecidas as considerações finais da pesquisa. 


\section{A FIRMA E A ECONOMIA DOS CUSTOS DE TRANSAÇÃO (ECT)}

Refletir sobre a atuação das firmas remete ao questionamento feito por Coase (1937) a respeito do porque as firmas existirem. Outra questão, proposta pelo mesmo autor, foi a seguinte: não seria mais fácil haver trocas de produtos e serviços em uma única grande firma, responsável pelo abastecimento de todo o mercado?

Os limites para a existência de uma única grande firma esbarram na capacidade de coordenação dos agentes econômicos (COASE, 1937; PENROSE, 1959). Em outras palavras, a capacidade administrativa desses agentes é limitada em termos de racionalidade (SIMON, 1945) e não depende, apenas, de fatores técnicos. Portanto, é preciso compreender a firma não apenas como um agente econômico que combina fatores de produção com uma eficiência máxima determinada previamente por uma dada tecnologia para a produção de bens e serviços. É necessário compreendê-la em um sentido mais amplo. Para Zawislak et al. (2009, p. 71), a firma é definida como "um composto de competências (tecnológicas, organizacionais e institucionais) cujo objetivo maior é garantir lucros extraordinários (obtidos pela superação das expectativas do mercado) que possam remunerar seus ativos acima das expectativas do mercado".

As transações ocorrem, basicamente, devido à necessidade que os agentes econômicos têm de buscar aquilo que não produzem. Se for mais barato comprar um insumo para a produção, uma firma tenderá a comprá-lo; se for mais barato produzir esse insumo, a firma assim o fará, desde que, evidentemente, disponha dos recursos necessários para tal. A administração das firmas não escapa do dilema fazer ou comprar e pode, ainda, tomar as duas posturas simultaneamente, estabelecendo, assim, estratégias organizacionais tão diversificadas quanto a habilidade dos seus gestores em efetivá-las. Se as firmas estiverem mais próximas do padrão concorrencial do mercado, incorrerão em maiores custos de transação, ao passo que, se estiverem mais próximas da hierarquia da firma, maiores serão os custos de inovação (ZAWISLAK, 2004).

Para Williamson (2010), o sistema econômico, ao funcionar a contento, utiliza-se de certos "mecanismos de governança". As estruturas de governança são três: o mercado, as formas híbridas e a hierarquia (WILLIAMSON, 1979). Segundo Williamson (1979), a governança via mercado se refere à organização das atividades econômicas pelo mecanismo de preços. Já a governança híbrida diz respeito àquele conjunto de acordos, arranjos ou contratos em que existe dependência bilateral para a organização da produção. Por fim, a 
governança via hierarquia acontece quando a firma decide trazer dentro das suas fronteiras aquelas atividades nas quais ela é mais eficiente do que o mercado. Nesta visão, a firma é vista como um mecanismo de governança (AOKI et al., 1989) entre clientes, empregados, executivos, funcionários, fornecedores, etc. (JENSEN, 2001).

O estudo da governança contratual da firma é abordado por meio do que na literatura se conhece como governança corporativa ${ }^{l}$ sendo este uma especificidade da noção mais geral de governança e consiste no conjunto de mecanismos pelos quais os fornecedores de capital da firma precisam se assegurar que receberam um retorno adequado sobre seus investimentos (SHLEIFER; VISHNY, 1997). No presente artigo, contudo, quando se utiliza o termo governança se estará referindo a uma das estruturas de governança de Williamson (1985, 2010), dentro da lógica que rege a Economia dos Custos de Transação e não sob a ótica da governança corporativa.

Pode-se afirmar que a ECT tem como marco inicial a publicação do artigo "The Nature of the Firm", escrito por Coase (1937). No entanto, essa ideia foi aprimorada a contento somente a partir dos trabalhos de Williamson (1971, 1975, 1985, 1996, 2002), que definiu as bases para a operacionalização desta teoria.

As bases desta operacionalização se estabelecem, por parte de Williamson (1971, 1975, 1979, 1985), em dois pressupostos básicos: um, a racionalidade limitada, ligada ao nível de conhecimento dos agentes, e o outro, o oportunismo, que balizam, justamente, seus comportamentos. Levando-se em conta o nível de informação (e ignorância) e, por conseguinte, a postura dos agentes econômicos, é possível caracterizar os três atributos que caracterizam todas as transações: a incerteza, a frequência e os ativos específicos. Essas dimensões permitem perfilar as estruturas de governança segundo as quais as transações acontecem. E é em função delas que se desenham os custos de transação.

Existem dois tipos de custos de transação que afetam, diretamente, o desempenho das firmas: (i) os custos de transação ex ante, que implicam negociar e fixar as contrapartidas e salvaguardas de contratos que, justamente, contornam as lacunas de informação conhecidas; e (ii) os custos ex post, relativos ao monitoramento, renegociação e adaptação dos termos contratuais a novas circunstâncias no decorrer de uma dada transação (WILLIAMSON, 1985).

\footnotetext{
${ }^{1}$ Uma vez que tal discussão não constitui o tema principal desta pesquisa, recomenda-se, para maiores aprofundamentos a respeito da expressão governança corporativa, revisar os trabalhos de Shleifer e Vishny (1997) e de La Porta et al. (1998).
} 
Esses custos estão presentes em todas as transações, ainda que em diferentes intensidades, sejam elas realizadas por meio do mecanismo mercado, sejam elas efetuadas por meio da hierarquia da firma. As transações mercantis "são o motivo fundamental para a existência das diferentes estruturas de governança", sentenciam Farina et al. (1997, p. 81). E esta governança, portanto, é o mecanismo de controle utilizado para garantir que as transações entre os agentes econômicos ocorram da maneira como foi contratada e planejada ex ante (GULATI; SINGH, 1998).

\subsection{A ESPECIFICIDADE DOS ATIVOS}

De certa forma, os ativos específicos como que resumem a essência da transação e a formação de seus custos. Na realidade, entende-se por ativos específicos aquele conjunto de características que fazem um processo ou um produto únicos para determinado fim. A condição de especificidade do ativo ocorre na situação em que, sendo reduzido o número de produtores capazes de ofertar determinado ativo, suas transações ocorrem em tal nível de especialidade que os tornam valiosos.

Marino (2001) é enfático ao afirmar que a especificidade dos ativos provoca o estabelecimento de uma relação de dependência entre as partes envolvidas em uma transação à medida que se elevam os graus de especificidade do negócio. Assim, quanto mais específica for a transação, maior será a demanda por coordenação; quanto maior a especificidade dos ativos, maiores serão as chances de ocorrência de ações oportunistas entre os agentes, que tendem a querer apropriar-se da quase-renda gerada.

Williamson (1991) distingue seis tipos básicos de especificidade dos ativos: a localização de um dado empreendimento; os ativos físicos; os ativos humanos; os ativos dedicados, representados pela relação de dependência do investimento com o retorno em virtude da dedicação a um agente particular ou a alguma atividade específica; a marca e a especificidade temporal - importante no caso de produtos perecíveis.

No Quadro 1 são apresentadas algumas das definições de ativos específicos.

Quadro 1: Algumas definições de ativos específicos

\begin{tabular}{|l|l|}
\hline \multicolumn{1}{|c|}{ Autores } & \multicolumn{1}{c|}{ Definições } \\
\hline Anderson (1985, p. 238) & $\begin{array}{l}\text { "...são adaptados a um determinado usuário (transação) e, portanto, são } \\
\text { valiosos apenas em uma estreita faixa de usos alternativos.” }\end{array}$ \\
\hline Williamson (1988, p. 70) & $\begin{array}{l}\text { "Refere-se ao grau em que um ativo pode ser transferido para usos alternativos } \\
\text { e por usuários alternativos sem sacrifício do valor produtivo.” }\end{array}$ \\
\hline Deegan (1997, p. 2-3) & "...são investimentos que geram retornos (retornos específicos) que estão \\
\hline
\end{tabular}




\begin{tabular}{|c|c|}
\hline & $\begin{array}{l}\text { condicionados à existência de uma coalizão particular. Há a noção de } \\
\text { dependência. Um investimento é especifico para uma determinada firma ou } \\
\text { coalizão se a sua implantação atual gera um retorno maior do que poderiam ser } \\
\text { em outros lugares. Isto é, seu uso atual é o uso mais eficiente." }\end{array}$ \\
\hline 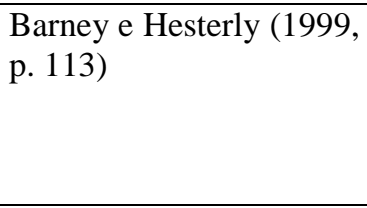 & $\begin{array}{l}\text { "...são investimentos que são muito mais valiosos em uma transação particular } \\
\text { em comparação com qualquer outra transação. Quanto maior a diferença de } \\
\text { valor entre este primeiro investimento de melhor uso (na atual transação) e o } \\
\text { segundo melhor uso (em alguma outra transação), mais específico o } \\
\text { investimento." }\end{array}$ \\
\hline Lyc & $\begin{array}{l}\text { "O grau para o qual o valor de um investimento está ligado ao comércio } \\
\text { contínuo entre um par particular de comerciantes." }\end{array}$ \\
\hline Morill (2003, p. & $\begin{array}{l}\text { "...é aquele que é necessário para ajudar uma determinada transação, mas não é } \\
\text { rapidamente transferível ou útil para qualquer outra transação." }\end{array}$ \\
\hline $\begin{array}{l}\text { Lamminmaki (2005, p. } \\
\text { 516) }\end{array}$ & $\begin{array}{l}\text { "... refere-se à medida que os investimentos em ativos (humanos ou físicos) são } \\
\text { específicos para uma relação comercial particular." }\end{array}$ \\
\hline $\begin{array}{l}\text { Verbeke e Kano (2012, } \\
\text { p. 1186) }\end{array}$ & $\begin{array}{l}\text { "...significa que ativos particulares, envolvidos em uma transação (ou tipo de } \\
\text { transação), não podem ser facilmente reutilizados em outras sem perda } \\
\text { significativa de valor econômico". }\end{array}$ \\
\hline
\end{tabular}

Fonte: Elaboração própria

A especificidade dos ativos constitui, portanto, um fator importante em termos de diferenciação entre firmas. Estes ativos são o que Amit e Schoemaker (1993) chamaram de ativos estratégicos. Mais do que isso, a especificidade de um ativo traz, em seu bojo, a existência de conhecimentos e tecnologias diferentes o suficientes para justificar sua produção e transação. E, ao mesmo tempo, quanto mais específicos forem os ativos, maior deverá ser a complexidade na coordenação das diferentes interfaces tecnológicas estabelecidas.

Em termos econômicos, não há como desvincular tais fatores. O aumento dos custos de transação, todavia, não é necessariamente prejudicial às organizações na medida em que lucros extraordinários tendem a ser decorrentes, justamente, da maior especificidade dos ativos envolvidos em uma transação. É a função coordenadora-gestora da organização que tomará as decisões pertinentes quanto ao melhor pacote de ativos a serem oferecidos aos clientes em cada situação.

\subsection{A RELAÇÃO ENTRE OS CUSTOS DE COORDENAÇÃO E A ESPECIFICIDADE DOS ATIVOS}

$\mathrm{Na}$ busca pela identificação dos determinantes das formas genéricas da organização, Williamson (1991) utiliza-se de determinados aspectos da economia institucional, do direito dos contratos e de elementos característicos da teoria organizacional. Existem mecanismos de coordenação e controle distintos, assim como conhecimentos e habilidades específicas necessárias à gestão de cada uma dessas formas. 
Quanto mais específica for a base de conhecimentos e tecnologias necessária para dar sustento ao conjunto de ativos que justifique uma firma, maiores tendem a ser os custos de coordenação. Por trás dessa relação está, na realidade, o fato de a firma, para manter e ampliar sua posição competitiva, ter que incorporar, cada vez mais, novas interfaces tecnológicas - o que exige um incremento de capacidade de organização e governança.

Segundo o modelo teórico escolhido para dar sustentação a este trabalho, espera-se que os resultados encontrados esbocem uma curva similar à que Williamson (1991) propôs na intenção de relacionar os custos de coordenação e a especificidade dos ativos. Ou seja, aceitase que a análise do peso dos ativos específicos na diferenciação das firmas que compõem o setor hoteleiro de Porto Alegre resulte em uma das curvas que define a Figura 1. Assume-se, de maneira específica, que o perfil dos hotéis investigados nesta pesquisa responda pela curva da Hierarquia - função $h(k)$ - pois assumiu-se que os 23 hotéis pesquisados são de fato firmas no sentido econômico do termo.

Figura 1: Especificidade de Ativos e Estruturas de Governança

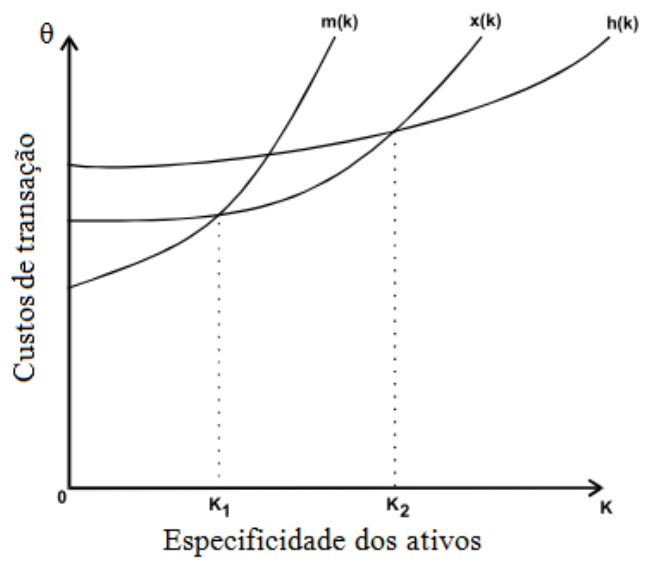

Onde:

$\mathrm{m}=$ Estrutura de governança via mercado

$\mathrm{x}=$ Estrutura de governança mista ou híbrida

$\mathrm{h}=$ Estrutura de governança hierárquica.

$$
\mathrm{K}=\text { grau de especificidade dos ativos }
$$$$
\theta=\text { custos de transação }
$$

Fonte: Williamson (1991)

Conforme se pode observar na Figura 1, as firmas se organizam de forma a constituir três tipos de estruturas de governança (WILLIAMSON, 1991). A representação esquemática da Figura 1 implica que, na hierarquia, sejam administrados ativos mais específicos do que aqueles transacionados nas estruturas híbridas e que os ativos desta sejam mais específicos do que aqueles compartilhados no mercado. Tal sequência reflete a chamada ineficiência marginal do mercado para coordenar ativos de alta especificidade. Os custos da organização 
interna da governança hierárquica são superiores, mas a especificidade dos ativos por ela administrados tende a ser também elevada - o que retorna à firma lucros extraordinários, conferindo a essa estrutura o status de firma. A estrutura de governança mista ou híbrida surge quando a relação entre custos de transação e especificidade dos ativos demanda uma estrutura de coordenação mais internalizada que o mercado, entretanto, ainda não tão hierárquica quanto à da firma.

$\mathrm{O}$ que se espera, a partir dessa abordagem teórica, é que no intervalo entre 0 e $K I$ (representado na Figura 1 pelo eixo da especificidade dos ativos), a estrutura de governança via mercado seja a mais eficiente, pois o nível de especificidade de ativos é o mais baixo e, consequentemente, o custo de governança também o será. Já no intervalo entre $K 1$ e $K 2$, há uma queda na eficiência da coordenação dos contratos via mercado, o que demanda uma estrutura de governança de tipo híbrido. A partir de $K 2$, a estrutura que apresenta a maior capacidade de sustentação dos custos de governança gerados pelo aumento da especificidade dos ativos é a hierárquica. As organizações que administram ativos muito específicos são melhor coordenadas por meio de estruturas que se aproximam da forma hierárquica, ao passo que aquelas cujos ativos são pouco específicos têm no mercado a melhor forma de coordenação devido aos baixos custos de governança próprios desse tipo de estrutura.

Ou seja, sob o ponto de vista organizacional, a ECT sugere a existência de uma melhor forma de coordenação para cada nível de especificidade de ativos. Isto é, à medida que os ativos específicos elevam-se, aumentam os custos das estruturas de governança. Isso ocorre, basicamente, porque, quanto mais específico o ativo, mais difícil será a sua recolocação no mercado em caso da transação ser desfeita e maior será a perda econômica no caso do ativo que era específico para um fim ser transferido para um uso alternativo (WILLIAMSON, 1991).

No extremo de maior especificidade dos ativos, encontra-se a estrutura hierárquica, em que a firma incorpora e mantém sob sua própria coordenação o nexo de contratos que administra. Essa posição traduz aquela firma que detém conhecimentos e tecnologias em tal nível de complexidade e especialidade que justifica uma estrutura autônoma de coordenação e, por exemplo, um departamento de inovação. No outro extremo, de menor especificidade, a estrutura de governança predominante é o mercado, onde a firma, por não deter maior especialidade, será, assim como tantas outras, mera tomadora de preços em um mercado altamente concorrencial de produtos de baixo valor agregado. Entre os dois extremos, a estrutura híbrida de governança tenta, justamente, casar a necessidade de mais especificidade 
e coordenação com a impossibilidade de realizar tal esforço de modo individual. Cadeias de suprimentos, subcontratados, redes de empresas são alguns exemplos que ajudam a entender os esforços de complementariedade entre agentes econômicos.

Em suma, quanto mais específicos os ativos, maiores serão os custos envolvidos em uma transação, fazendo com que, em média, os preços cobrados a fim de recuperar os investimentos realizados nesse processo sejam mais elevados. Mais do que isso, uma determinada especificidade de ativos sugere a existência de uma estrutura de governança definida, cujos custos de coordenação e, consequentemente, os preços dos produtos e serviços oferecidos estejam adequados à expectativa de valor manifestada pelos clientes. Esses tenderão a pagar o preço cobrado pelo oferecimento de um determinado nível de ativos específicos se perceberem o valor desses ativos. Em outras palavras, quanto maior o valor agregado percebido pelo cliente, maiores serão o nível de especificidade do produto e a necessidade de coordenar um conjunto de interfaces tecnológicas, tudo isso representado por um preço mais elevado.

$* * *$

A literatura dedicada à relação entre os ativos específicos e os custos de transação é vasta (MONTEVERDE; TEECE, 1982; ANDERSON, 1985; ANDERSON; COUGHLAN, 1987; JOHN; WEITZ, 1988; KLEIN et al., 1990; GOSH; JOHN, 2005; CRUZ, et al., 2011; TAVARES; PORTUGAL, 2013). Entretanto, segundo De Vita e Tekaya (2015), essas pesquisas usualmente se focam em firmas que operam na indústria, deixando uma lacuna gritante no conhecimento desta relação no contexto de firmas relacionadas ao setor de serviços.

De forma mais específica, de acordo com Lamminmaki (2005), em se tratando do setor hoteleiro, há uma necessidade deste tipo de pesquisas. Assim sendo, o presente artigo tenta preencher uma parte dessa lacuna, na qual são necessários trabalhos que analisem a relação dos ativos específicos e os custos de transação no setor hoteleiro.

\section{MÉTODO E PROCEDIMENTOS OPERACIONAIS DE PESQUISA}

Para realizar o presente estudo, foi utilizada uma série de dados disponíveis nos sites dos 23 hotéis pesquisados e também da Secretaria Municipal de Turismo. Ademais, foram 
estabelecidas conversas telefônicas com os gestores de alguns desses hotéis na intenção de confirmar a existência de alguns dos ativos exibidos nos endereços eletrônicos dos mesmos.

O presente estudo pode ser classificado como predominantemente qualitativo (ainda que se apoie em evidências de caráter quantitativo) com abordagem descritiva, uma vez que busca descrever, estruturar e medir características descritivas em relação a uma dada problemática de pesquisa (MALHOTRA, 2006). A pesquisa descritiva permitiu uma análise apurada das características dos hotéis selecionados, de forma a compreender e analisar seus ativos específicos.

A cidade de Porto Alegre contava, em 2009, com três hotéis cadastrados na categoria Luxo, 20 na categoria Superior, 29 na categoria Turístico e 20 na categoria Econômico, não havendo hotéis na categoria Superluxo. De outra parte, apesar de haver na cidade os chamados hotéis Simples, estes não eram catalogados no site da Secretaria de Turismo. Neste trabalho, traçou-se um comparativo das especificidades dos ativos relativos aos hotéis pertencentes às categorias Luxo e Superior, pois nessas categorias a diferenciação entre as firmas é mais saliente. Os hotéis enquadrados nas outras categorias apresentam maior homogeneidade em termos de preços e especificidade de ativos, aproximando-os da estrutura de governança do tipo mercado.

Os hotéis pesquisados por ocasião desta pesquisa foram os seguintes:

- Categoria Luxo: Deville Aeroporto, Plaza São Rafael e Sheraton Porto Alegre.

- Categoria Superior: Bela Vista Service Residence, Blue Tree Towers, Duque Center, Embaixador, Everest Porto Alegre, Holiday Inn, Intercity Premium, Master Palace, Mercure Apartment (Beverly Hills, Il Giardino e Manhattan), Novotel, Piazza Navona Flat, Plaza Porto Alegre (Plazinha), Porto Alegre City, Porto Alegre Residence, Quality Porto Alegre, Ritter Porto Alegre, Swan Towers e Swan Molinos Flat.

\subsection{MENSURANDO AS ESPECIFICIDADES DOS ATIVOS NA HOTELARIA DE PORTO ALEGRE}

A hospedagem é um dos principais fatores a ser contabilizado em uma viagem, sendo responsável pelo maior percentual dos gastos geralmente efetuados pelos viajantes (YOUEL, 2002). Conforme Webster (1992), em um ambiente competitivo pautado pelos avanços nas telecomunicações, no processamento de informações e pela ampliação das opções de escolha 
à disposição dos consumidores, os desafios relativos às ferramentas de comunicação utilizadas pelas organizações são cada vez maiores.

A compra de produtos de viagem, em geral, é associada a um alto risco se comparado a produtos tangíveis. Desta forma, consumidores procuram estar bem informados, sendo a internet um dos canais mais utilizados (BUHALIS; JUN 2011). Diante disso, o setor da hotelaria vem sofrendo mudanças significativas, requerendo soluções práticas para seus clientes de modo a agregar valor aos serviços prestados, o que passa, necessariamente, pelo aumento da especificidade dos ativos transacionados. As características físicas dos hotéis, a qualidade dos serviços prestados e os aspectos humanos envolvidos em uma negociação constituem fatores determinantes no momento da escolha do serviço de hospedagem.

Nesse sentido, os fatores de diferenciação são cada vez mais explorados por meio dos endereços eletrônicos dos hotéis - uma interface que permite, em muitos casos, o primeiro contato entre firma e cliente. Por outro lado, o retorno obtido pelo cliente só tende a vir com a confirmação in loco das informações previamente coletadas na internet.

A cidade de Porto Alegre, alvo da presente pesquisa, contava com cerca de 13.000 leitos e uma taxa de ocupação de $71 \%$ (FOHB, 2009) no momento da realização da etapa de coleta de dados para deste trabalho, no segundo semestre de $2009^{2}$. Porto Alegre é reconhecida como a terceira cidade mais visitada por estrangeiros no Brasil no quesito eventos, negócios e convenções (MTUR, 2010). Ademais, estima-se que a cidade tenha sido visitada por cerca de 5,4 milhões de turistas no ano de 2007, de acordo com as informações da Secretaria de Turismo de Porto Alegre.

Observando a atual conjuntura socioeconômica, em que a internet é um dos principais meios de comunicação, os hotéis tendem a manter seus sites atualizados e com as informações relevantes disponíveis para que seja fácil e rápida a consulta por parte de qualquer cliente potencial (BUHALIS; JUN, 2011). Por isso, a pesquisa em questão teve por finalidade inventariar os ativos dos hotéis enquadrados nas categorias Luxo e Superior e relacioná-los com o fator custos de governança, analisando se estão adequados às respectivas categorias, segundo as proposições da ECT.

\footnotetext{
${ }^{2}$ Ainda que dados mais atualizados estejam disponíveis para consulta, optou-se pela utilização de um referencial que correspondesse ao período de realização da parte empírica deste estudo, a fim de melhor contextualizar o ambiente de negócios no qual estava inserido o setor da hotelaria naquele momento. Entende-se que, a despeito do ano em que se deu a coleta e análise dos dados, seja ele 2009, 2014 ou 2015, o argumento defendido neste trabalho não sofre alteração.
} 


\subsection{PROCEDIMENTOS DE PESQUISA}

Os passos seguidos a fim de catalogar e avaliar os ativos específicos oferecidos em cada um dos 23 hotéis pesquisados foram os seguintes:

\section{Passo 1}

A partir da tabulação dos ativos exibidos nos endereços eletrônicos (sites) dos 23 hotéis investigados, confirmou-se a classificação dos mesmos segundo os parâmetros específicos da indústria hoteleira. O conjunto dos ativos utilizados na diferenciação entre as firmas foi categorizado segundo a "matriz de classificação"3 do Ministério do Turismo (Deliberação Normativa n. 429, de 23 de abril de 2002) nos seguintes itens: Postura Legal; Atendimento ao Hóspede; Setor Habitacional; Áreas Sociais; Alimentos e Bebidas; Lazer; Serviços Adicionais e Localização (vide Apêndice 1). Já os itens Segurança, Saúde e Higiene, Conservação/Manutenção, Portaria/Recepção, Acessos e Circulações, Comunicações, Reuniões/Escritório Virtual e Ações Ambientais não apresentaram diferenças entre as firmas analisadas, não representando, portanto, itens que pudessem ser tomados como ativos específicos.

\section{Passo 2}

Definidas as características gerais, optou-se por descartar aquelas consideradas obrigatórias para que o hotel fosse classificado nas categorias Luxo e Superior segundo a matriz de classificação. Algumas características também foram descartadas enquanto critério de diferenciação por se encontrarem em todos os hotéis considerados neste estudo. São tidos como padrão de mercado, por exemplo, serviços como "site com tradução em outras línguas"

\footnotetext{
${ }^{3}$ A Embratur, visando definir parâmetros para instituir o sistema de classificação dos meios de hospedagem resolve, entre outros, o Artigo 3. Modificando o Regulamento dos Meios de Hospedagem, o Manual de Avaliação e a Matriz de Classificação criados pela Deliberação Normativa $\mathrm{n}^{\circ}$ 387, de 28 de janeiro de 1998, publicada no Diário Oficial da União ${ }^{\circ} 27$, de 09/02/98, define os seguintes aspectos básicos:

I - modifica o Regulamento Geral dos Meios de Hospedagem;

II - altera integralmente o processo de classificação dos meios de hospedagem; Hospedagem

III - procede alterações no Manual de Avaliação e na Matriz de Classificação dos Meios de

IV - incorpora ao Regulamento Geral dos Meios de Hospedagem, como anexos I e II os impressos denominados, respectivamente, "Ficha Nacional de Registro de Hóspedes - FNRH" e "Boletim de Ocupação Hoteleira - BOH";

V - Incorpora, igualmente, no Regulamento do Sistema Oficial de Classificação dos Meios de Hospedagem os anexos III e IV, denominados Manual de Avaliação e Matriz de Classificação;

VI - consolida disposições dispersas na legislação, concernente à atividade hoteleira. Fonte: http://www.feriasvivas.org.br/wpsite/wp-content/uploads/2014/09/deliberacao-020423-429.pdf
} 
ou a possibilidade de realização de "reservas online". Ou seja, não se poderia tomar tais fatores como representativos de um diferencial entre os hotéis enquadrados nas categorias em estudo por não se tratar de ativos específicos para os fins deste estudo.

\section{Passo 3}

Ao total foram analisados 69 ativos específicos capazes de proporcionar diferenciação entre os hotéis pesquisados. Tais ativos foram distribuídos nas seguintes categorias: Postura legal; Atendimento ao hóspede; Setor habitacional; Área social; Alimentos e bebidas; Lazer; Serviços adicionais e Localização.

Após essa tabulação, realizou-se uma consulta a dois especialistas em hotelaria, de modo que fosse possível atribuir pesos (zero, 1 e 2) a cada um desses ativos. Quanto maior a pontuação estabelecida, maior a especificidade do ativo e, em consequência, em tese, maiores os custos envolvidos na manutenção desse ativo e maior o preço da diária. A intenção dessa consulta era a de que se procedesse a uma aproximação quali e quantitativa dos critérios de decisão envolvidos na escolha de um hóspede em potencial, quanto a sua percepção em termos de valor em relação a um dado hotel. A classificação proposta pelos dois especialistas teve como base o levantamento dos ativos envolvidos nas transações segundo Williamson (1971), que relaciona os ativos (k) com três níveis de especificidade, em que:

$\mathrm{k}=0$ (zero), significa ativos não específicos, isto é, totalmente reutilizáveis;

$\mathrm{k}=\mathrm{m}$, significa um nível supostamente intermediário de especificidade e;

$\mathrm{k}=\infty$, significa ativos altamente específicos (idiossincráticos).

Traduzidos para uma escala de pontuação numérica, montamos o seguinte esquema:

$0($ zero $)=$ ativo reutilizável;

1 ponto $=$ ativo de especificidade intermediária;

2 pontos $=$ ativo idiossincrático

Do resultado dessa consulta aos especialistas, esboçou-se uma curva de utilidade (Figura 3, a ser exibida na seção em que se discute os resultados da pesquisa) a partir da média entre os pesos atribuídos aos ativos específicos, a qual retrata as relações entre os 
preços médios cobrados pelos hotéis, para cada diária, em relação à pontuação dos seus ativos específicos.

Para preservar a identidade dos hotéis, adotamos uma classificação em ordem alfabética conforme a quantidade de ativos específicos, sendo "A", a organização que possuía menor quantidade de ativos específicos e "X" a organização que possuía a maior quantidade de ativos específicos. Os hotéis da categoria Superior vão de "A" até "T", já as letras U, V e $\mathrm{X}$ correspondem aos hotéis pertencentes à categoria Luxo, o que confirma a maior quantidade de ativos específicos oferecidos por esse tipo de hotéis.

\section{Passo 4}

Como não foi possível obter informações fidedignas a respeito dos custos de governança dos 23 hotéis investigados, por ser uma informação sigilosa e que nem todos chegam a mensurar de forma exata, decidiu-se obter uma aproximação quanto a essa informação a partir da análise dos endereços eletrônicos de cada hotel, onde foi possível avaliar os preços médios que cada um deles cobra por uma diária. Na falta de um memorial de custos, tomou-se o preço das diárias como fator de comparação entre os hotéis.

Portanto, o fator "custos" (como medida da estrutura de governança e dos custos de coordenação) foi substituído pelo fator "preços", na montagem dos gráficos que amparam a discussão dos resultados. Tal decisão fundamenta-se em Williamson (1991), segundo o qual, quanto maior a especificidade dos ativos, maiores os custos de coordenação e, em decorrência, maiores deverão ser os preços cobrados pelas fïrmas a fim de retornar o investimento despendido na especificidade desses ativos.

A suposição contida nesta decisão é a de que, a fim de cobrir custos de coordenação maiores, devem ser cobrados preços mais altos que esses custos, caso contrário, estariam comprometidos os lucros e a sobrevivência daquelas organizações as quais não fossem capazes de cobrar preços superiores aos custos de coordenação. Ou seja, assume-se que preços de diárias maiores estão associados a custos de governança também maiores. De modo a integrar o eixo $y$ das Figuras 2 e 3 (a serem exibidas na discussão dos resultados), ponderase os preços médios das diárias dos hotéis com base no seguinte cálculo:

Preço da diária $=(\underline{\text { diária "standard single" }+ \text { diária do quarto "double" mais caro }})+$ café + garagem 
Em que:

Café da manha: valor para uma pessoa

Garagem: valor de uma diária

Por meio dessa fórmula, padronizou-se os preços médios que cada um dos 23 hotéis consultados cobra de seus hóspedes. Nessa conta, descartaram-se os (poucos) hotéis que dispunham de apartamentos triplos e também os únicos dois que ofereciam suíte presidencial, em função dos elevados preços cobrados por tais acomodações e porque não havia critério de comparação com os outros hotéis da cidade. Em alguns casos, quando as informações sobre preços das diárias constantes nos sites não eram claras, foi preciso o contato telefônico. Em outros, o contato telefônico também foi necessário a fim de se esclarecer o significado e a utilidade de certos ativos pouco comuns, ou com denominação em língua estrangeira, o que poderia gerar resultados confusos. Também houve a necessidade de solicitar a metragem dos apartamentos e suítes, já que, de acordo com a matriz de classificação dos meios de hospedagem, existe uma metragem mínima para cada categoria.

Uma das limitações desse método ficou por conta da não observância das condições e tarifário para grupos e realização de eventos nesses hotéis. Para os especialistas consultados, trata-se de fatores decisórios importantes na escolha da hospedagem. As diárias coletadas nos sites são aquelas aplicadas aos casos mais corriqueiros e dizem respeito a reservas individuais, sendo que muitas vezes, grande parte da ocupação e, portanto, do faturamento de um hotel, resulta da hospedagem de grupos e da realização de eventos.

\section{RESULTADOS E DISCUSSÃO}

Os hotéis estudados neste trabalho podem ser tipificados como firmas, isto é, estruturas de governança verticais ou hierárquicas, pois assumem o controle sobre a coordenação dos serviços prestados visando à economia de custos de transação. As 23 firmas consideradas (20 hotéis da categoria Superior e 3 hotéis da categoria Luxo) internalizam a função coordenadora-gestora e, por meio de investimentos em inovação, acabam escapando da competição mais acirrada imposta pelo mercado. Além disso, são firmas que se diferenciam entre si a partir da estruturação de um conjunto único de ativos específicos e, portanto, têm seus custos de governança mais elevados. Conforme indicado pelo modelo teórico, a expectativa em relação aos resultados dessa pesquisa era a de que os hotéis da categoria Luxo 
exibissem um nível mais elevado de ativos específicos em relação àqueles da categoria Superior. Da mesma forma, esperava-se que os custos de coordenação também fossem maiores nos hotéis de Luxo.

Com vistas à obtenção de um perfil com a distribuição dos preços das diárias dos 23 hotéis pesquisados, elaborou-se o gráfico representado pela Figura 2. Esse gráfico exibe a relação entre os preços das diárias com uma projeção da especificidade dos ativos envolvidos nessas transações. Na Figura 2, tem-se a distribuição dos preços cobrados pelas diárias dos 20 hotéis da categoria superior (A, B, C, D, E, F, G, H, I, J, K, L, M, N, O, P, Q, R, S e T), mais os 3 hotéis da categoria luxo (U, V e X). Alerta-se para fato de que o eixo dos ativos específicos apresentado na Figura 2 ainda não é representativo da quantidade de ativos específicos que cada hotel oferece. Como a diária mais baixa é a do hotel $\mathrm{B}(\mathrm{R} \$ 139,50)$, estimou-se que a menor quantidade de ativos específicos dessa listagem fosse oferecida por esse hotel. Depois, viria o hotel F ( $\mathrm{R} \$ 187,00 /$ diária) e assim por diante, até chegar-se ao hotel $\mathrm{X}(\mathrm{R} \$ 571,50 /$ diária $)$ que, em tese, ofereceria a maior quantidade de ativos específicos aos seus hóspedes.

Figura 2: Linha da tendência dos preços médios cobrados pelos 23 hotéis pesquisados em função da projeção da especificidade dos ativos.

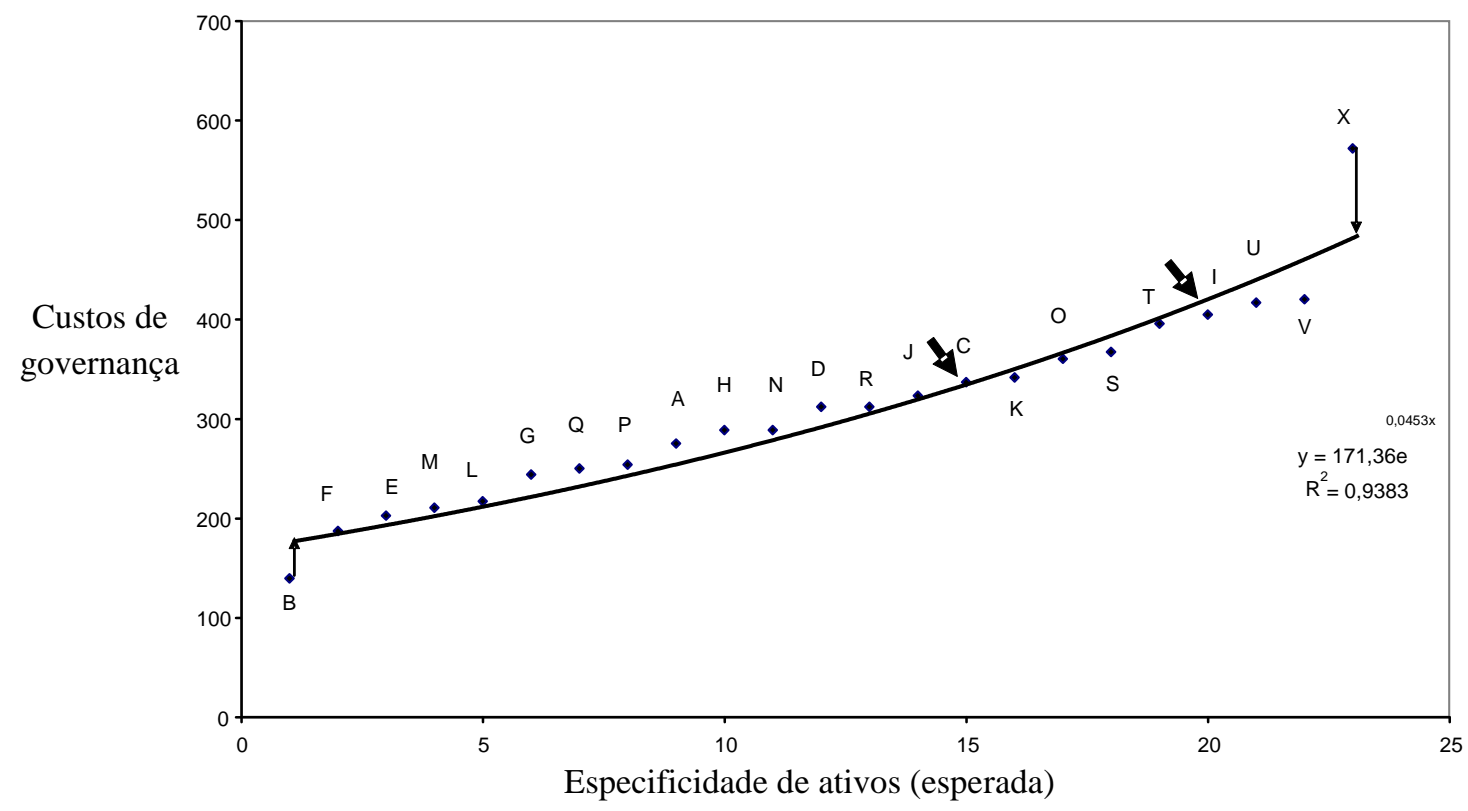

Fonte: Elaboração própria 
Conforme sugere a ECT, o hotel B tende a ser aquele cujos custos de coordenação são os mais baixos entre a população investigada. Da mesma forma, a especificidade dos ativos administrados pelo hotel B deve ser a menor entre os 23 hotéis pesquisados. No outro extremo do gráfico, está o hotel X, que cobra os maiores preços médios por diária. Por oferecer aos clientes a maior quantidade de ativos específicos e, a fim de coordená-los adequadamente, o hotel X é aquele que deverá incorrer nos maiores custos de coordenação.

Em função da diferenciação entre as firmas, é possível notar que os hotéis T e I, por exemplo, apesar de pertencerem à categoria Superior, cobram preços compatíveis àqueles dos hotéis da categoria Luxo. A expectativa em relação aos hotéis T e I é que, dentre os hotéis da categoria Superior, venham a ser aqueles que oferecem a maior quantidade de ativos específicos à disposição de seus hóspedes. Além disso, estimou-se que, por supostamente oferecerem uma gama de ativos específicos potencialmente superiores a todos os outros hotéis da categoria Superior, os hotéis T e I venham a ter maiores custos de coordenação, o que, em tese, justificaria a cobrança de preços mais elevados por uma diária em suas acomodações.

\subsection{A PARTICIPAÇÃO DOS ESPECIALISTAS EM HOTELARIA}

A atribuição de pontos aos ativos de cada hotel, segundo a orientação dos dois especialistas em hotelaria que foram consultados para esta pesquisa, gerou curvas que se aproximam das Figuras 1 e 2 (curva essa que não levava em consideração os pesos ponderados de cada ativo, constituindo-se em mera projeção).

A título de ilustração, exemplifica-se como se deu a pontuação dos ativos específicos na visão de um dos especialistas consultados: a presença de "serviço de mordomo", por exemplo, foi considerada por este especialista como sendo um ativo específico que merecia pontuação 2, visto ser um serviço altamente especializado e diferenciado, que poucos hotéis, somente nos estratos mais altos, teriam condição de oferecer. Outro ativo que recebeu peso 2 na pontuação desse especialista foi a instalação de isolamento acústico. Já a presença do ativo específico "varanda" recebeu peso 1 na visão desse especialista, visto ser um ativo que alguns hotéis disponibilizam, nem todos, mas que não chega a ser tão específico quanto o serviço de mordomo, por exemplo.

De acordo com as ponderações propostas pelos especialistas, foi possível montar a Tabela 1, baseada no somatório da pontuação obtida por cada um dos ativos específicos disponibilizados pelos 23 hotéis pesquisados: 
Tabela 1: Classificação dos hotéis em termos de ativos específicos segundo especialistas do setor hoteleiro.

\begin{tabular}{|c|c|c|c|c|c|}
\hline Posição & $\begin{array}{l}\text { Diária } \\
\text { média }\end{array}$ & Especialista 1 & Especialista 2 & $\begin{array}{c}\text { Média dos } \\
\text { especialistas }\end{array}$ & Hotéis \\
\hline $1^{\circ}$ posição & 275,00 & 5 & 4 & 4,5 & $\mathrm{~A}(4,50)$ \\
\hline $2^{\circ}$ posição & 139,50 & 9 & 8 & 8,5 & $\mathrm{~B}(8,50)$ \\
\hline $3^{\circ}$ posição & 336,50 & 11 & 8 & 9,5 & $\mathrm{C}(9,50)$ \\
\hline $4^{\circ}$ posição & 187,00 & 11 & 9 & 10 & $\mathrm{~F}(10,50)$ \\
\hline $5^{\circ}$ posição & 202,50 & 13 & 10 & 11,5 & $\mathrm{E}(11,50)$ \\
\hline $6^{\circ}$ posição & 312,00 & 13 & 10 & 11,5 & $\mathrm{D}(11,50)$ \\
\hline $7^{\circ}$ posição & 244,00 & 16 & 13 & 14,5 & $\mathrm{G}(14,50)$ \\
\hline $8^{\circ}$ posição & 288,50 & 16 & 14 & 15,0 & $\mathrm{H}(15,00)$ \\
\hline $9^{\circ}$ posição & 217,00 & 17 & 15 & 16,0 & $\mathrm{~L}(16,00)$ \\
\hline $10^{\circ}$ posição & 404,50 & 17 & 15 & 16,0 & $\mathrm{I}(16,00)$ \\
\hline $11^{\circ}$ posição & 210,50 & 18 & 15 & 16,5 & $\mathrm{M}(16,50)$ \\
\hline $12^{\circ}$ posição & 323,00 & 19 & 15 & 17,0 & $\mathrm{~J}(17,00)$ \\
\hline $13^{\circ}$ posição & 341,50 & 19 & 16 & 17,5 & $\mathrm{~K}(17,50)$ \\
\hline $14^{\circ}$ posição & 288,50 & 23 & 18 & 20,5 & $\mathrm{~N}(21,00)$ \\
\hline $15^{\circ}$ posição & 254,00 & 24 & 20 & 22,0 & $\mathrm{P}(22,00)$ \\
\hline $16^{\circ}$ posição & 360,00 & 24 & 20 & 22,0 & $\mathrm{O}(22,50)$ \\
\hline $17^{\circ}$ posição & 250,00 & 25 & 21 & 23,0 & $\mathrm{Q}(23,00)$ \\
\hline $18^{\circ}$ posição & 312,00 & 25 & 23 & 24,0 & $\mathrm{R}(24,00)$ \\
\hline $19^{\circ}$ posição & 395,50 & 27 & 24 & 25,5 & $\mathrm{~T}(25,50)$ \\
\hline $20^{\circ}$ posição & 367,00 & 29 & 25 & 27,0 & $\mathrm{~S}(27,00)$ \\
\hline $21^{\circ}$ posição & 416,50 & 31 & 26 & 28,5 & $\mathrm{U}(28,50)$ \\
\hline $22^{\circ}$ posição & 420,00 & 35 & 32 & 33,5 & $\mathrm{~V}(33,50)$ \\
\hline $23^{\circ}$ posição & 571,50 & 36 & 32 & 34,0 & $X(34,00)$ \\
\hline
\end{tabular}

Fonte: Elaboração própria.

Essa tabela traz, na primeira coluna, o posicionamento de cada hotel (do $1^{\circ}$ ao $23^{\circ}$ ) em relação à quantidade ponderada de ativos específicos disponibilizados aos hóspedes. Na segunda coluna está descrito o preço médio da diária, um dado que, em tese, deveria ser proporcional à especificidade dos ativos envolvidos nas transações. Na terceira coluna, foi listada a pontuação em termos de ativos específicos conforme a apreciação do especialista 1 . A quarta coluna leva em consideração a pontuação sugerida pelo especialista 2. A quinta coluna representa a média da pontuação entre os dois especialistas, para cada hotel. Finalmente, na sexta coluna, foi proposto um código sequencial para os hotéis, de A (para aquele com a menor média de ativos específicos) até $\mathrm{X}$ (o hotel com a maior quantidade de ativos específicos). 
Com base no volume de ativos específicos coordenados por cada hotel, montou-se uma classificação em quatro grupos (I, II, III e IV) estruturados conforme a ponderação de cada um dos especialistas consultados por ocasião desta pesquisa.

Segundo o especialista 1, os grupos ficariam assim divididos:

Grupo I: entre 5 e 13 ativos específicos;

Grupo II: entre 16 e 19 ativos específicos;

Grupo III: entre 23 e 25 ativos específicos e;

Grupo IV: entre 27 e 36 ativos específicos.

Segundo o especialista 2, os hotéis ficariam assim agrupados:

Grupo I: entre 4 e 10 ativos específicos;

Grupo II: entre 13 e 16 ativos específicos;

Grupo III: entre 18 e 23 ativos específicos e;

Grupo IV: entre 24 e 32 ativos específicos.

O Grupo I envolve os hotéis A, B, C, D, E e F; o Grupo II engloba os hotéis G, H, I, J, K, L e M; o Grupo III tem os hotéis N, O, P, Q e R e o Grupo IV consiste nos hotéis S, T, U, V e X. Na média, os hotéis do grupo IV são os que oferecem a maior quantidade de ativos específicos e, por conseguinte, deveriam cobrar os maiores valores médios por diária.

$\mathrm{Na}$ ponderação de ativos específicos feita pelo especialista 1, o Hotel A obteve 5 pontos. Por meio da análise do endereço eletrônico desse hotel, foram identificados 4 ativos que, em tese, seriam específicos. No entanto, como o especialista 1 atribuiu peso 2 a um desses 4 ativos, e peso 1 aos demais, na ponderação, o hotel A acabou com 5 pontos. Por outro lado, o especialista 2 atribuiu apenas 1 ponto a cada um dos 4 ativos específicos exibidos no site do hotel $\mathrm{A}$, de modo que, na visão desse especialista, o hotel A obteve 4 pontos. Portanto, a média das avaliações feitas pelos dois especialistas em relação ao hotel A ficou em 4,5 pontos.

Mesmo oferecendo apenas 4,5 pontos em termos de ativos específicos, o hotel A cobra o equivalente a $\mathrm{R} \$ 275,00 /$ diária. O hotel que ocupa a $2^{\mathrm{a}}$ posição no ranking dos ativos específicos cobra, em média, R \$139,50 por uma diária, sendo que oferece aos seus hóspedes 8,5 pontos em termos de ativos específicos. A resposta para o fato de que o hotel A, que obteve uma pontuação menor (4,5 pontos) em relação à especificidade de seus ativos, cobra um valor superior $(\mathrm{R} \$ 275,00)$ àquele do hotel $B(R \$ 139,50)$, que oferece praticamente o dobro em termos de ativos específicos (8,5 pontos), está além das pretensões deste artigo. Claro que, uma vez que se está considerando apenas duas categorias de hotéis (Superior e 
Luxo), é possível considerar que há uma tênue fronteira entre ambas. Fronteira essa que, ao ser difícil de ser identificada pelo consumidor, pode ser transferida, como vantagem, por uma ou outra empresa, para o preço ${ }^{4}$.

Cada hotel oferece um conjunto único de ativos específicos (aqui tomados como aspectos de diferenciação) que, quando comparados por meio da análise dos seus sites, podem indicar, ou não, vantagens competitivas, dependendo do tipo de cliente que navega em tais domínios. Essa diferenciação se observa, claramente, até mesmo através da classificação realizada pelos especialistas do setor, que possuem visões diferentes e, portanto, curvas de valores diferentes na avaliação de um conjunto de ativos específicos similar. Apesar da diferença apresentada entre os especialistas, foi identificado que itens importantes para a facilidade do turismo de negócios (principal motivo de viagem apresentado pela demanda turística na cidade de Porto Alegre, conforme dados da Secretaria Municipal de Turismo) tiveram pontuações idênticas entre os especialistas.

Há hotéis como o $\mathrm{C}$ e o I que apesar de apresentarem baixa quantidade de ativos específicos (9,5 e 16 pontos) e estarem classificados, respectivamente, nos grupos I e II, cobram valores de diárias compatíveis com os hotéis situados nos grupos III e IV. O grupo IV, inclusive, é composto por hotéis que oferecem até 36 pontos de ativos específicos. Tal observação abre a possibilidade de que se façam suposições como as seguintes:

a) há ativos específicos relativos a estes hotéis que não são exibidos em seus endereços eletrônicos, tampouco são mencionados quando em consultas telefônicas e que, apesar de existirem, não foram computados na realização dos gráficos ora apresentados, ou;

b) esses hotéis cobram, realmente, preços superiores à média de seus grupos para o oferecimento de um pacote de ativos específicos similares, o que, em tese, os faria lucrar mais que a média do setor.

O quesito marca ou grife não foi levado em consideração na classificação dos hotéis pesquisados. É possível que, em virtude desse fator, algum hotel venha a cobrar preços de diárias mais elevados ainda que ofereça um pacote de ativos específicos que se assemelhe àquele oferecido pelas demais firmas que compõem o setor e estão no mesmo nível de oferta de ativos específicos. Este seria um ponto importante a ser levado em conta em estudos

\footnotetext{
${ }^{4}$ A suspeita de que o hotel A ofereça ativos específicos que sustentem o maior valor da diária em relação ao hotel B não foi, no entanto, confirmada pela análise dos ativos constantes no site do hotel A nem pelas ligações telefônicas feitas a esse hotel, o que representa uma limitação do método ora empregado no sentido de oferecer uma explicação ao fato.
} 
futuros visto que a escolha de um hotel, muitas vezes, está subordinada à imagem e lembrança que se tem de uma grife conhecida.

De outra parte, hotéis como o T e S, de categoria Superior estão localizados no grupo IV, juntamente com os hotéis de categoria Luxo. Eles tanto oferecem uma quantidade maior de ativos específicos quanto cobram valores próximos aos da categoria Luxo, diferenciandose em relação à média daqueles hotéis situados na categoria Superior.

\subsection{ANÁLISE GRÁFICA A PARTIR DAS MÉDIAS DOS ESPECIALISTAS}

A soma dos pontos dos ativos (aspectos de diferenciação) de cada um dos 23 hotéis investigados, ponderados pela apreciação de cada especialista, gerou uma pontuação média progressiva conforme se observa na Figura 3. Trata-se de um gráfico que estabelece uma relação entre os preços das diárias (tomados em lugar dos custos de governança) e a pontuação dos ativos específicos oferecidos pelos hotéis analisados.

Figura 3: Preços das diárias (tomados como custos de governança) Vs. especificidade dos ativos



Fonte: Elaboração própria.

A argumentação contida neste trabalho baseia-se na suposição de que nenhum hotel opera abaixo da linha potencial dos custos mínimos de operação no setor, isto é, para estar no mercado, essas firmas devem, necessariamente, obter lucros. O que indica esse limite potencial na Figura 3 são as linhas tracejadas, que ligam os pontos $\mathrm{B}, \mathrm{Q}$ e V, chegando até o ponto X. Em tese, segundo a classificação dos especialistas em hotelaria, os hotéis B, Q e V 
operariam com menores lucros, pois cobram as menores diárias para a quantidade de ativos que oferecem. Já a linha contínua (que tangencia o hotel S) representa a tendência dos preços médios do setor e, quando confrontada com a curva da Figura 1 (o gráfico de Williamson), representa a curva dos custos médios de governança das firmas que operam neste setor.

\subsection{EVIDÊNCIAS EMPÍRICAS}

Tece-se, agora, algumas observações quanto ao que propõe a teoria em confronto com os dados empíricos aqui apresentados. Segundo a ECT, os pontos que se distanciam da curva principal, situando-se acima da mesma, representam organizações que, por algum motivo, administram estruturas de governança que apresentam custos mais elevados em relação ao padrão do setor, isto é, estruturas organizacionais cujos custos de coordenação são maiores do que o mínimo esperado para a coordenação daquela quantidade de ativos específicos. Isso, de certa forma, pode demonstrar uma certa margem de desconhecimento, por parte dos agentes econômicos, acerca de seus custos, o que oferecer e o que cobrar.

Nesse sentido, aceita-se o que foi chamado de evidência empírica 1: na Figura 3, os hotéis representados pelos pontos situados acima da linha principal (contínua), tais como os hotéis $\mathrm{C}$ e $\mathrm{D}$, podem auferir lucros maiores do que, por exemplo, os hotéis representados pelas letras E e F. A Figura 3 evidencia que os hotéis C e D cobram preços mais altos pelo oferecimento de um pacote de ativos específicos que é semelhante àqueles oferecidos pelos hotéis E e F, conforme se depura da análise do eixo da especificidade dos ativos.

A evidência empírica 2 aponta para o seguinte: em função do preço das suas diárias, hotéis como os representados pelas letras C e I, na Figura 3, provavelmente oferecem pacotes de ativos específicos compatíveis, respectivamente, com os hotéis F e M. Contudo, essa quantidade a mais de ativos específicos que eles possivelmente oferecem ao consumidor não são exibidos nos seus endereços eletrônicos tampouco foram confirmados por meio de conversas telefônicas. Para se respeitar o método que foi aplicado às outras firmas, os hotéis $\mathrm{C}$ e I aparecem no gráfico como se estivessem cobrando um preço muito alto por uma quantidade menor de ativos específicos.

De outra parte, o hotel S, que ocupa a $20^{a}$ posição na pontuação dos ativos específicos, tangencia a linha principal na Figura 3. Isto significa que, segundo a classificação dos especialistas, respeitando-se a evidência 1 e, aceitando-se como válida a comparação de ativos proposta neste trabalho, tende a valer mais a pena para um cliente hospedar-se no hotel $\mathrm{S}$ do 
que no hotel T, por exemplo. Afinal, o hotel $\mathrm{S}$ oferece ao cliente 27 ativos específicos pelo preço de $\mathrm{R}$ \$ 367,00 ao passo que o hotel T oferece uma pontuação de 25,5 ativos e cobra $\mathrm{R}$ \$ 395,00 pela diária. Os hotéis $\mathrm{T}$ e $\mathrm{S}$ oferecem uma quantidade de ativos específicos mais elevada que a média da sua categoria (Superior), permanecendo junto ao grupo IV, onde estão os hotéis tipo Luxo. Eles também cobram valores de diárias similares aos cobrados pela categoria Luxo devido à maior quantidade de ativos que é oferecida aos clientes.

Uma observação semelhante diz respeito à comparação entre os hotéis $\mathrm{V}$ e $\mathrm{X}$. Na visão dos especialistas, apenas meio ponto (hotel $\mathrm{V}=33,5$ ativos específicos; hotel $\mathrm{X}=34$ ativos específicos) os separa. Contudo, ao passo que o hotel V cobra, em média $\mathrm{R} \$ 420,00$ por uma diária, o hotel X cobra $\mathrm{R} \$ 571,50$ por, praticamente, o mesmo pacote de ativos específicos. Além do fator grife, outros fatores, como a própria localização do hotel, por hipótese, tende a fazer com que a administração cobre um preço mais elevado por um conjunto de ativos similar ao do concorrente mais próximo.

Daí que, por meio deste estudo, pôde-se confirmar a validade da ECT para a análise do comportamento das firmas em relação à administração de seus ativos específicos $V s$. seus custos de governança. Afinal, pôde-se comprovar que, em função de um certo grau de especificidade de ativos, há uma correspondência no que diz respeito a um dado nível de organização necessária a fim de administrar esses ativos. Pode-se afirmar, portanto, que o nível de especificidade dos ativos determina o tipo de organização e os custos de governança praticados pela firma. Quanto maior a especificidade dos ativos envolvidos numa transação, maiores serão os custos de coordenação da estrutura de governança necessária para administrar tais ativos a contento.

\section{CONSIDERAÇÕES FINAIS}

Como qualquer outra teoria, a Economia dos Custos de Transação tem sido aprimorada ao longo do tempo, o que implica ter passado pelos estágios pré-formal e semiformal (WILLIAMSON, 2010). Hoje, em tese, esta teoria se encontra no estágio de formalização plena (WILLIAMSON, 2010). Portando, utilizar a ECT no intuito de entender a dinâmica de um setor de serviços, mais especificamente, do setor de hoteleira, pode ser uma 
contribuição alinhada ao progresso desta teoria. Isto porque as pesquisas que se utilizam do ferramental da ECT, usualmente, se focam em firmas industriais, deixando uma lacuna de conhecimento na área de serviços (DE VITA e TEKAYA, 2015). Fato que, também, é confirmado por Lamminmaki (2005) quando ressalta a necessidade de estudos dentro do setor hoteleiro, sendo algumas exceções as pesquisas de Hemmington e King (2000), EspinoRodríguez et al., (2014) e De Vita e Tekaya (2015).

Em relação ao cumprimento do objetivo deste trabalho, atesta-se que foram mensuradas as especificidades dos ativos de 23 hotéis das categorias Luxo e Superior localizados em Porto Alegre/RS. Esses ativos específicos foram relacionados com os custos de governança, a fim de estabelecer o peso dos mesmos na diferenciação das firmas que compõem esse setor econômico. Como não se dispunha dos custos de governança dessas firmas (e esta foi uma das principais limitações desta pesquisa - as outras foram expostas na seção de método), foram utilizados os preços médios cobrados por suas diárias. Para tanto, baseou-se, principalmente, nas informações disponibilizadas nos endereços eletrônicos (sites) de cada hotel pesquisado.

Dados os resultados desta pesquisa, pode-se afirmar que é possível, por meio de estudos empíricos, medir a especificidade dos ativos e compará-la aos custos de governança, considerando-os como elementos reveladores dos custos de transação. No segmento hoteleiro de Porto Alegre, por exemplo, há hotéis que se enquadram exatamente nas condições previstas pela Economia dos Custos de Transação. Baseado no método empregado foi possível explicar em grande medida o comportamento esperado das firmas. Isso confirma a validade, a acurácia e a relevância da ECT para a realização de estudos desta natureza.

Estes resultados guardam relação com os achados de Espino-Rodríguez e Lai (2014), que, ao estudarem o setor hoteleiro de Taiwan, encontraram que a estratégia de diferenciação está estreitamente relacionada com a necessidade de incorporar ativos mais específicos. Por esta razão, as atividades da firma geralmente são menos terceirizadas (isto é, neste caso há menos governança via mercado). Neste setor, uma estratégia baseada na diferenciação envolve foco no cliente e alta qualidade nos serviços oferecidos (ESPINO-RODRÍGUEZ; LAI, 2014). No entanto, estes resultados mudam quando a especificidade dos ativos é introduzida como variável moderadora (ESPINO-RODRÍGUEZ; LAI, 2014). Assim sendo, na presença destes ativos, os hotéis optam por internalizar as suas atividades.

Contudo, quando testada esta mesma relação no setor hoteleiro da Tailândia, a ECT ofereceu menor poder explicativo (PROMSIVAPALLOP et al., 2015). No setor hoteleiro 
desse país também foi identificada a presença de ativos altamente específicos, ainda que os hotéis optassem por terceirizar atividades-chave como restaurante e transporte dos passageiros (PROMSIVAPALLOP et al., 2015).

A contradição entre os resultados de Espino-Rodríguez e Lai (2014) e Promsivapallop et al., (2015) já tinha sido ressaltada por Olsen et al., (2008). Para este último, as teorias originadas em países desenvolvidos (Ex.: Taiwan), podem não se aplicar a países em desenvolvimento (Ex.: Tailândia) devido às diferenças existentes nesses ambientes de negócios. Para o caso desta pesquisa, entendemos que ao ser Porto Alegre uma das cidades mais desenvolvidas do Brasil, é provável que o ambiente de negócios seja mais parecido àquele de um país desenvolvido. Isto explicaria porque os resultados encontrados confirmam a hipótese tradicional da ECT, da mesma forma que os resultados de Espino-Rodríguez e Lai (2014).

Por fim, recupera-se a informação de que o quesito marca ou grife não foi considerado na classificação dos hotéis pesquisados, sendo esta outra limitação do presente estudo. Diante disso, é de se esperar que algum hotel possa cobrar preços de diárias mais elevados que os concorrentes, mesmo que ofereça um pacote de ativos específicos que se assemelhe àquele oferecido pelas demais firmas que compõem o setor. Este seria um ponto importante a ser levado em conta em estudos futuros visto que a escolha de um hotel, muitas vezes, está subordinada à imagem e lembrança que se tem de uma grife conhecida. Além do fator grife, outros fatores, como a própria localização do hotel tendem a fazer com que a administração cobre um preço mais elevado por um conjunto de ativos similar ao do concorrente mais próximo - o que também poderia ser considerado na agenda de pesquisas futuras. Cabe, por fim, ressaltar que esta pesquisa se limita a um conjunto de hotéis da cidade de Porto Alegre; esta restrição implica precaução perante alguma tentativa na generalização dos dados para, por exemplo, todo o Brasil. 


\section{REFERÊNCIAS}

ASSOCIAÇÃO BRASILEIRA DAS INDÚSTRIAS DE HOTÉIS - ABIH. Regulamentação do Sistema Oficial de Classificação de Meios de Hospedagem, 2002. Disponível em: <http://www.abih.com.br/principal/classificacao/regulamento_sistema.pdf >. Acesso em: 10 jun. 2009.

AMIT, R.; SCHOEMAKER, P. Strategic assets and organizational rent. Strategic Management Journal, Chichester, v. 14, n.1, p. 33-46, 1993.

ANDERSON, E. The Salesperson as Outside Agent or Employee: A Transaction Cost Analysis. Marketing Science, 4 (Summer), p. 234-54, 1985.

ANDERSON E.; COUGHLAN A. International market entry and expansion via independent or integrated channels of distribution. Journal of Marketing, v. 51, n. 1, p. 71-82, 1987.

AOKI, M., GUSTAFSSON, B.; WILLIAMSON, O.E. The firm as a nexus of treaties. London: Sage Publications, 1989.

BRASIL. Deliberação normativa n. 429 de 23 de abril de 2002. Novo Sistema de Classificação dos Meios de Hospedagem. Disponível em: <http://www.abih.com.br/principal/classificacao/embratur.pdf >. Acesso em: 10 jun. 2009.

BARNEY, J.; HESTERLY, W. Organizational economics: understanding the relationship between organizations and economic analysis. In Clegg, S.R., Hardy, C. and Nord, W.R. (eds.), Handbook of Organization Studies. London: Sage, p. 115-147, 1996.

BUHALIS, D.; JUN, S. H. E-toursim. Contemporary Tourism Reviews. 2011.

COASE, R. The nature of the firm. Economica, Oxford, v. 4, n. 16, p. 386-405, 1937.

CRUZ, A. P. C.; COSTA, F.; ANTONOVZ, T.; GARCIAS, P. M. Condicionantes da Especificidade de Ativos das Maiores Empresas do Brasil sob Ótica da Teoria Econômica dos Custos de Transação. Contabilidade Vista \& Revista, v. 22, p. 155-180, 2011.

DEEGAN, C. Efficient management remuneration plan design: a consideration of specific human capital investment. Accounting and Finance, Oxford, v. 37, n. 1, p. 1-40, 1997.

DE VITA, G; TEKAYA, A. Hotel outsourcing under asset specificity: "The good, the bad and the ugly". Tourism Management, v. 47, p. 97-106, 2015.

ESPINO-RODRÍGUEZ, T.; LAI, P. Activity outsourcing and competitive strategy in the hotel industry. The moderator role of asset specificity. International Journal of Hospitality Management, v. 42, p. 9-19, 2014.

FARINA, E.; AZEVEDO; SAES, M. Competitividade: Mercado, Estado e Organizações. São Paulo: Singular, 1997. 
FORUM DE OPERADORES HOTELEIROS DO BRASIL - FOHB. InFohb, 23 ano 4. Disponivel em: <http://www.fohb.com.br/info/INFOHB\%20-\%20Edicao\%2023.pdf>. Acesso em: 06 maio 2015.

GHOSH M.; JOHN G. Strategic fit in industrial alliances: an empirical test of governance value analysis. Journal of Marketing Research. v.42, n. 3, p.346-357, 2005.

GULATI, R.; SINGH, H. The architecture of cooperation: managing coordination costs and appropriation concerns in strategic alliances. Administrative Science Quarterly, Ithaca, v. 43, p. 781-814, 1998.

HEMMINGTON, N.; KING, C. Key dimensions of outsourcing hotel food and beverage services. International Journal of Contemporary Hospitality Management, v.12, n. 4, p. 256-261, 2000.

HOCAYEN-DA-SILVA, A.; TEIXEIRA, R. Em busca de uma abordagem integradora para analisar vantagem competitiva no setor hoteleiro. Revista Brasileira de Gestão e Desenvolvimento Regional. Taubaté, v. 4, n. 4, p. 172-192, set/ dez, 2008.

JENSEN, M. A theory of the firm: governance, residual claims, and organizational forms. Harvard University Press, 2001.

KLEIN S.; FRAZIER G.; ROTH V. A transaction cost analysis model of channel integration in international markets. Journal of Marketing Research, v. 27, v.2, p. 196-208, 1990.

LA PORTA, R.; SHLEIFER, A.; LOPEZ-DE-SILANES F.; VISHNY, R. Law and finance. Journal of Political Economy, v.106, n. 6, p. 113-1155, 1998.

LAMMINMAKI, D. Why do hotels outsource? An investigation using asset specificity. International Journal of Contemporary Hospitality Management, Yorkshire, v. 17, n. 6, p. 516-528, 2005.

LYONS, B.R. Specific investment, economies of scale, and the make-or-buy decision: a test of transaction cost theory. Journal of Economic Behaviour and Organization, Amsterdam, v. 26, n. 3. p. 431-443, 1995.

MALHOTRA, N. K. Pesquisa de marketing: uma orientação aplicada. 4. ed. Porto Alegre: Bookman, 2006.

MARINO, M. K. Análise da evolução da relação contratual entre produtor e agroindústria citrícola, após a extinção do contrato padrão. In: II Workshop brasileiro de gestão de sistemas agroalimentares, Ribeirão Preto, SP. Anais... Ribeirão Preto, SP: PENSA/FEA/USP, 1999.

MASTEN, S. E. The organization of production: evidence from the aerospace industry. Journal of Law and Economics, Chicago, v. 27, n.2, p. 403-417, 1984.

MINISTERIO DO TURISMO - MTUR. Anuário Estatístico de Turismo 2010 - Volume

37, ano base $2009 . \quad$ Disponível em:

E\&G Economia e Gestão, Belo Horizonte, v. 15, n. 41, Out./Dez. 2015 
http://www.dadosefatos.turismo.gov.br/export/sites/default/dadosefatos/anuario/downloads_a nuario/Anuxrio_2010_-_Ano_Base_2009__Final_internet.pdf. Acesso em 15 junho 2009.

MORILL, C.; MORILL, J. Internal auditors and the external audit: a transaction cost perspective. Managerial Auditing Journal, Bingley: West Yorkshire v. 18, n. 6/7 p. 490504; 2003.

MONTEVERDE, K.; TEECE D. J. Supplier switching costs and vertical integration in the automobile industry. Bell Journal of Economics, Murray Hill v. 13, n. 1, p. 206-213, 1982.

O'CONNOR, P. Distribuição da informação eletrônica em turismo e hotelaria. São Paulo: Bookman, 2001.

OLSEN, M.; SHARMA, A.; ECHEVESTE, I.; TSE, E. Strategy for hospitality businesses in the developing world. Hospitality Review, v. 26, n.1, p. 32-46, 2008.

PENROSE, E. The Theory of the Growth of the Firm. New York: Oxford University Press, 1959.

PORTO ALEGRE CONVENTION E VISITORS BUREAU. Número de leitos Porto Alegre, 2009. Disponível em: <http://www.poaconvention.com.br >Acesso em 06 jul. 2009.

PROMSIVAPALLOP, P.; JONES, P.; ROPER, A. Factors influencing hotel outsourcing decisions in Thailand: modifications to the transaction cost economics approach. Journal of Hospitality \& Tourism Research, v. 39, n.1, p. 32-56, 2015.

SECRETARIA DE TURISMO DE PORTO ALEGRE. Perfil do turista nacional na cidade de Porto Alegre - Relatório de pesquisa. (2007). Disponível em: <http://www2.portoalegre.rs.gov.br/turismo>. Acesso: em 06 de jul 2009.

SHLEIFER, A.; VISHNY, R. A survey of corporative governance. Journal of Finance, v. 52, n.2, p. 737-783, 1997.

SIMON, H. A. Administrative Behavior. Nova York, Free Press, 1945.

SINDICATO DA HOTELARIA E GASTRONOMIA DE PORTO ALEGRE. Dados estatísticos hotelaria de Porto Alegre, 2009. Disponível em: 〈http://www.shrbs-rs.org.br>, Acesso em 29 mai. 2009.

TAVARES, T. S.; PORTUGAL, M. Especificidades de ativos e alianças estratégicas no setor farmacêutico brasileiro. In: XVI Simpósio de Administração da Produção, Logística e Operações Internacionais, 2013, São Paulo: Fundação Getúlio Vargas, 2013.

VERBEKE, A.; KANO, L. The transaction cost economics theory of the family firm: familybased human asset specificity and the bifurcation bias. Entrepreneurship Theory and Practice, Calgary, v. 36, n. 6, p. 1183-1205, 2012. 
VILLALONGA, B.; MCGAHAN, A. M. The choice among acquisitions, alliances, and divestitures. Strategic Management Journal, Chichester, v.26, n. 13, p.1183-1208, 2005.

WEBSTER, J.F. The changing role of marketing in the corporation. Journal of Marketing, Chicago, v.56, n. 4, p. 1-17, 1992.

WILLIAMSON, O. Transaction Costs Economics: The Governance of Contractual Relations. Journal of Law and Economics, Cary, v. 22, n. 5, p. 223-261, 1971. York, 1975.

Markets and Hierarchies: Analysis and Antitrust Implications. Free Press: New The Economic Institutions of Capitalism. Free Press: New York, 1985.

. The logic of economic organization. Journal of Law, Economics and Organization, Cary, v. 4, n. 1, p. 65-93, 1988.

Comparative Economic Organization: The Analysis of Discrete Structural Alternatives. Administrative Science Quarterly, Ithaca, v. 36 (June), p. 269-296, 1991.

Economics and organization: A primer. California Management Review, Berkeley v. 38, n. 2, p. 131-146, 1996.

The Theory of the Firm as Governance Structure: From Choice to Contract. The Journal of Economic Perspectives, Nashville, v. 16, n. 3, p. 171-195, 2002.

Transaction Cost Economics: The Natural Progression. The Journal of Retailing, New York, v. 86, n. 3, p. 215-226, 2010.

WOODWARD, S. A transaction cost analysis of banking activity and deposit insurance. Cato Journal, Washington, v. 4, n. 3, p. 683-699, 1988.

YOUELL, R. Turismo uma introdução. São Paulo: Contexto, 2002.

ZAWISLAK, P. In: Nota Técnica In: Clegg, S., Hardy, C. \& Nord, D. (Orgs) Handbook de estudos organizacionais. São Paulo: Atlas, v. 3, p. 180-185, 2004.

ZAWISLAK, P.; LARENTIS, F.; MACHADO, C. ANDRADE, A. Firm's Innovation Expectation, Potential and Actions: Impressions on the Japanese Videogame Console Market. Journal of Technology Management and Innovation, Santiago, v. 4, n. 4, p. 69 - 81, 2009. 
Apêndice 1 - Categorias utilizadas, com base na matriz de classificação do Ministério do Turismo (2009)

\begin{tabular}{|c|c|}
\hline Categoria & Detalhamento \\
\hline Postura Legal & Fechadura Eletrônica \\
\hline \multirow{5}{*}{$\begin{array}{l}\text { Atendimento ao } \\
\text { Hóspede }\end{array}$} & Correio de Voz \\
\hline & Mapa e Localização no site \\
\hline & Serviço de Mordomo \\
\hline & Informações da Cidade \\
\hline & Concierge \\
\hline \multirow{23}{*}{ Setor Habitacional } & Apto categ. luxo met. sup. $20 \mathrm{~m}^{2}$ \\
\hline & Apto categ. sup. met. $17 \mathrm{~m}^{2}$ \\
\hline & Suíte categ. luxo met. sup. $31 \mathrm{~m}^{2}$ \\
\hline & Suíte categ. sup. met. $27 \mathrm{~m}^{2}$ \\
\hline & Apto. antialérgico \\
\hline & Apto. não fumantes \\
\hline & Aptos. conjugados \\
\hline & Suíte \\
\hline & Internet gratuita \\
\hline & Internet wireless \\
\hline & Cofre eletrônico \\
\hline & Banheira de imersão \\
\hline & Banheira de hidromassagem \\
\hline & 02 ou mais linhas telefônicas \\
\hline & Isolamento acústico \\
\hline & Sala de jantar \\
\hline & Mesa de trabalho \\
\hline & Varanda \\
\hline & Secador de cabelo \\
\hline & Travesseiro de pluma de ganso \\
\hline & Vista panorâmica \\
\hline & Hospedagem para animais \\
\hline & Cama extra \\
\hline \multirow{9}{*}{ Area Social } & Internet wireless \\
\hline & Internet gratuita \\
\hline & Estacionamento com manobrista \\
\hline & Estacionamento gratuito \\
\hline & Ar condicionado central \\
\hline & Restaurante \\
\hline & Restaurante internacional \\
\hline & Música ao vivo \\
\hline & Cafeteria \\
\hline
\end{tabular}

\begin{tabular}{|c|c|}
\hline Categoria & Detalhamento \\
\hline \multirow{10}{*}{ Lazer } & Churrasqueira \\
\hline & Sala de jogos \\
\hline & Piscina \\
\hline & Piscina térmica \\
\hline & Quadra de tênis \\
\hline & $\begin{array}{l}\text { Área de fitness com } \\
\text { instrutor }\end{array}$ \\
\hline & Academia \\
\hline & Sauna \\
\hline & $\begin{array}{l}\text { Jacuzzi de } \\
\text { hidromassagem }\end{array}$ \\
\hline & Massagista \\
\hline \multirow{11}{*}{$\begin{array}{l}\text { Serviços } \\
\text { adicionais }\end{array}$} & Berçário \\
\hline & Transfer \\
\hline & Business center \\
\hline & Guest oficce \\
\hline & Lavanderia \\
\hline & Loja de jóias e pedras \\
\hline & Cia aérea \\
\hline & Shopping \\
\hline & Spa \\
\hline & Locadora de veículos \\
\hline & Salão de beleza \\
\hline \multirow{10}{*}{ Localização } & Anchieta (Aeroporto) \\
\hline & Moinhos de Vento \\
\hline & Centro \\
\hline & Bela Vista \\
\hline & Auxiliadora \\
\hline & Higienópolis \\
\hline & Rio Branco \\
\hline & Praia de Belas \\
\hline & Três Figueiras \\
\hline & Independencia \\
\hline
\end{tabular}

